\title{
'Belonging' in Young Adult Dystopian Fiction: New Communities Created by Children
}

\author{
Patricia Kennon
}

In this paper I will discuss the role that young adults play in the creation of new communities governed by young people in four dystopian novels set during the fragmentation of society in the near future. I will focus on novels narrated by or focalised through the perspective of young female protagonists, as these narratives offer intriguing explorations of young women's utopian capacity for leadership and for re-visioning traditional power relations and social structures. In their exploration of their own subjectivities, the young female protagonists must address the claims of individual self-actualisation while re-assessing the validity and appeal of traditional hierarchical systems of authority located in a radically changed and hostile world. Novels such as Meg Rosoff's How I Live Now (2004), O.T. Nelson's The Girl Who Owned a City (1995), Marcus Sedgwick's Floodland (2000) and Gary Kilworth's The Electric Kid (1994) explore how the impact of the abrupt absence of parental control and adult surveillance results in the young protagonists' forced creation and development of new concepts of community, family and 'belonging'. Inherited hierarchical systems of individual identity and the larger social and political world are challenged during the characters' struggles for survival in these novels as the young protagonists display considerable courage, creativity and 'heroic' attributes in their efforts to survive and also to protect other younger children in their care. As such, these dystopian stories offer opportunities to explore gender role stereotypes and their reformulation by young people during situations which require both the conventional 'masculine' qualities such as leadership, bravery and endurance and also 'feminine' attributes such as nurturing, collaborative teamwork and compassion.

While utopia is the dream of the imagined 'good place', an ideal world that by its example urges us to improve ourselves, dystopia is the story of the 'bad place', an ominous nightmare scenario warning us of repressive futures that seem all too disturbingly possible and plausible. Lyman Tower Sargent defines the dystopia as 'a non-existent society described in considerable detail and normally located in time and space that the author intended a contemporaneous reader to view as considerably worse than the society in which that reader lived' (1994, p.9). Carrie Hintz argues that because of the romanticised views of Western childhood which persist in writing for young children, utopias tend to predominate in children's literature, while a more troubling and darker atmosphere is far more common in young adult literature, where dystopian young adult fiction provides a promising vehicle to depict adolescents' political and social awakening and their mediation with the authority of adults and inherited institutions, exploring 'the way individuals position themselves in reference to a wider collective' (Hintz 2002, p.254).

Yet these dystopian works are also characterised by a deep ambivalence regarding young people's potential to create repressive regimes of power as they renegotiate tensions between personal independence and the claims of a communal and co-operative identity. In this genre, optimistic possibilities for emancipatory agency seem intertwined with pessimistic acknowledgement of the limitations for the transformation of society and relationships between generations. The creative and confident alternative systems of child-centric leadership, embodying young people's autonomy of government, are depicted as constantly under threat from being overwhelmed by and refashioned into conservative and inherited patterns of disciplinary discourses.

The construction of childhood operating in this dystopian genre is profoundly informed by the ambivalent capacity of the figure of the child itself to serve both as symbol of hope for a better, more egalitarian future and as a helpless victim of oppressive power dynamics created and maintained by authoritarian and reactionary adults. Kay Sambell argues that the traditional innocence attributed to child protagonists means that 'they are likely to be viewed as easy prey, tragically ill-equipped to survive in the aggressively hostile world of the imagined future. Their survival thus risks seeming like an implausible escape: a jarring and clichéd device to present a hopeful alternative that undermines or counteracts the narrative logic of the preceding story' (2004, p.253).

How I Live Now, The Electric Kid, Floodland and The Girl Who Owned a City share this tendency to depict the darker experiences of young female characters struggling to survive in dystopian futures. Daisy, the narrator of 
How I Live Now, is faced with the breakdown of English society during the chaos of wartime; in Floodland, Zoe, a refugee, must search for her parents in a world where rising sea levels have resulted in isolated pockets of dangerously over-crowded remaining land; in the postdisaster scenario of The Girl Who Owned a City, Lisa is faced with the challenge of reconstructing society after all people over the age of twelve are killed by a mysterious plague; and in The Electric Kid the marginalised female protagonist Hotwire lives in a city-dump in an alienating and technology-driven future-Britain. Yet these novels also explore the empowering possibilities of young people's reformulation and re-energising of the social forces and patriarchal institutions surrounding them.

In Disturbing the Universe: Power and Repression in Adolescent Literature, Roberta Seelinger Trites has argued that while children's literature in general tends to affirm the protagonist's sense of self and personal power, what Trites has termed the 'postmodern' impulse of young adult fiction inherently involves a more critical dimension with necessarily uncomfortable consequences for the authority figures (usually adult) being so challenged. I would agree with Trites' assertion that power and powerlessness are integral to YA fiction's exploration of the construction of identity, and that this fiction commonly recognises that power can act as both a repressive and a productive force as filtered through protagonists' negotiation, resistance and acceptance of various social and political patriarchal discourses. Trites maintains that adolescent protagonists 'must learn about the social forces that have made them what they are' and must also learn to 'negotiate the levels of power that exist in the myriad social institutions within which they must function, including family; school; the church; government; social constructions of sexuality, gender, race, class; and cultural mores surrounding death' (2000, p.3). Although Trites' discussion addresses the general field of young adult realistic fiction, I would contend that her conclusions regarding the challenging possibilities for reflective exploration of both the productive and repressive nature of power is also highly applicable to the genre of dystopian fiction for young readers and its engagement with identity politics.
In Ways of Being Male: Representing Masculinities in Children's Literature and Film,

John Stephens has addressed the intersections between power, gender identity and self-actualisation in children's literature and has convincingly highlighted the ideological and didactic aspects embedded in most texts for young readers which 'in effect, reproduce the dominant culture's ideological status quo by confirming the macrostructure of the relationship between the adult and the child' (Stephens 2002, xv). I agree with Stephens' overall conclusion that the field of literature for young people is embedded in ideological issues of control and power, and I would maintain that this inherently conservative dimension tempers the extent to which dystopian young adult fiction proposes futures re-imagined and enriched by children's leadership and transformative governance. Michel Foucault's influential declaration of the fundamental and inevitable interrelation of space and power relations in Discipline and Punish: The Birth of the Prison (1979) also offers an intriguing framework in which to examine the disciplinary impact of spatial politics on identity politics and the gendered construction of social and space in dystopian fiction. Similarly, I believe that Kevin Walsh's argument that 'Any attempt to develop a sense of place should be concerned with the emphasis on diachrony, an emphasis on the temporal depth of places' (Walsh 1992, p.150) provides a lens through which dystopian texts seek to analyse processes of change and stability within physical landscapes, buildings and monuments, as well as the internal gradations of characters' understanding and engagement with the past and with the concept of alterity.

The above observations regarding the geography of power are especially true of how female characters re-evaluate and re-organise inherited places and spaces in dystopian young adult fiction, as traditional patriarchal institutions of conservative adult-child power dynamics are re-signified and adapted to meet the needs of young people. The young protagonists of threatening near-future scenarios in the four novels under discussion cannot survive in areas infected by violence, war and plague and sites of natural disasters and thus must move as refugees to populate other areas once controlled and administered by adults. The four novels share a common theme of displacement, as their 
protagonists are forced to leave their homes and ultimately to create or adapt an alien and hostile environment to their physical and psychological needs. Venerable patriarchal bastions of adult control and authority such as cathedrals (Floodland) and schools (The Girl Who Owned a City) must be inhabited and utilised in radical and creative ways through the sheer necessity of surviving without adult protection or guidance.

The compelling ideal of the family home as a site of origin interpolated in conservative space and power dynamics, comes under particular scrutiny in dystopian young adult fiction. Emotional investment in the family and the domestic and traditionally 'feminine' space of the home by adolescent protagonists usually involves a degree of nostalgia for this communal and 'secure' space, the crucible of early personal development. The trope of homelessness affords a means by which the imaginative pull of this idealisation of the home is interrogated in relation to group and individual female identities. That houses and communities are vulnerable to violence, destruction and abandonment in these novels suggests young people's mixed anxieties and desires about leaving home and, by extension, the strictures of adult rules. Many critics have noted the archetypal 'home-away-home' pattern of adventure and exploration in children's literature and the subsequent ambivalent attachment to the home as both a space of reassuring stability and of frustrating constraint. For example, Ann Alston, discussing the division of space of the home in many works in children's literature, attributes the common re-production of traditional 'learnt' models of the creation and organisation of homes by child characters to the power of the didactic 'ideal' of this private yet social sphere: "To make something "home-like" the child has to submit to archetypal signs that maintain the myth of the ideal home. The home and the ordering of spaces and objects within it remain static, and this is because children internalise the adult ideal' (2005, p.28).

Each of the four novels explores how female protagonists reconfigure and challenge hegemonic discourses of home, family, authority and domestic and public space. Competing claims between personal individuality and communal identity, and female characters' revisioning of the spatial and cultural politics of traditional hierarchical power relations between adults and children are central to all four novels' exploration of identity politics, in particular the maintenance of gender codes, in the dystopian near-future. The emphasis of feminist work on the social construction of gender roles as being always inflected and intersected by differences of class, ethnicity, race, sexuality etc., has involved a re-evaluation of the hegemonic narrative structure of the hero story in children's literature, interpellated in patriarchal power-space relations such as the ostensibly polar conflict between traditional constructs of masculine and feminine, reason and emotion, and civilisation and nature. A politics of transformation enabling a more expansive experience of agency for young female protagonists in future societies involves a review of patriarchal presumptions of appropriately 'feminine' conduct as associated with harmonious co-operation and occupation of the private, domestic sphere rather than with the autonomous and dynamic roles of leader and explorer in these novels.

In O.T. Nelson's The Girl Who Owned a City (1995), after the local children are left parentless, and the energetic protagonist, Lisa, demonstrates a determined commitment to adapting the patriarchal ideology of the family structure to her own political ends. Initially only caring for herself and her younger brother, Lisa begins to be concerned for other children's welfare when her own plans are endangered. Throughout the novel, Lisa decides that she will share her knowledge and the rewards of her initiative, but not for free: she believes that her friend Jill has needlessly handicapped herself by her efforts to altruistically protect and care for younger orphan children. Lisa's conscious preference for assuming the status of paternal authority while rejecting any association with a nurturing, maternal role informs all her planning and dreams of restoring traditional civilisation, as she remembers it. She first sets up a neighbourhood militia of children based in their own homes and then occupies the local school to establish a new 'city' of 'child-families' (p.88) that she insists on controlling. While the children's collective colonisation of the school complex could be seen as providing an optimistic manifestation of their empowered agency and revolutionary claim to a space traditionally dominated by adult authority, the tension between communal rights and the pre-eminence of Lisa's 
individual will overshadows this utopian and subversive establishment of children's voices and power.

Although the title of Nelson's book contains tantalising hints of the subversive potential for the enriching results of female leadership, Lisa's insistence on her superior leadership for reconstructing their lives in Glenbard, the school-turned 'indoor city' of children (p.120) which she regards as her own property, results in a type of benevolent tyranny which she imposes on the hundreds of children who eventually come to live there, despite the fact that all the children help to build and maintain Glenbard. Her defence of her behaviour, that 'Freedom is more important than sharing'(p.144), implies that her freedom from questioning and criticism is more important than the rights of the other children in decisions regarding the government of their community. Despite their complaints about Lisa's highhanded assumption of control, the other children do not challenge the legitimacy of the self-appointed committee of male and female children who administer the city, thus implying either their implicit acceptance of the value of both male and female government or a more pessimistic conclusion regarding these children's political apathy and passivity in reconfiguring their new society.

Nelson does consider how protagonists maintain conservative gender stereotypes of both masculine and feminine conduct in their comprehension of the limited range of suitable possible activities in which they can engage. For example, one of Lisa's closest advisors secretly longs for the more peaceful and nurturing profession of a farmer but instead reconciles himself to becoming the military general of the city. Similarly, the 'general of Wheaton', a neighbouring town, does not believe that a mere girl could be the leader of a city of children. Lisa is depicted as so aggravated and insulted by this chauvinism that she 'smashed her fist into [his] face', (p.190), thus engaging in the very violence that she deplores as a solution to their problems. Although Lisa declares that she considers male leaders who call themselves 'kings' as reintroducing obsolete hierarchical systems from the Dark Ages, her city is similarly based on feudal, conservative and reactionary lines. Indeed, many of the children under her care enthusiastically embrace this rigidly hierarchical system of her 'naturally' appointed leadership when they come to regard her as a messianic figure at the end of the novel, 'a leader who has come back from the dead (pp.195, 193) when she survives after being shot by the rival tribal leader and usurper of the city, Tom Logan.

The Girl Who Owned A City depicts a world where the child characters face starvation and violence without adult support or protection. However, the novel contains many complacent omissions of distressing issues which the children may have to face: there is no explanation for the sudden plague which kills all older people and the surviving children never show any concern that they might contract the illness when they turn twelve; the children's bereavement of their older relatives and friends is never depicted; there is no mention of any danger of decay or how to address the rotting corpses of all the people who died from the plague and thus there is no need by the children to confront this repugnant reminder of mortality, or to deal with such distressing markers of 'abjection', according to Julia Kristeva's term for that which 'disturbs identity, system, order. What does not respect borders, positions, rules. The in-between, the ambiguous, the composite' (Kristeva 1982, p.10). Therefore Nelson's exploration of young people's capacity to cope with the challenges of creating and maintaining a new social system is ideologically flawed by the erasure of questions concerning the extent to which these survivors deal with the threat of mortality and their own deaths. Furthermore, although the novel spans a time period of more than a year, none of the child characters is depicted as physically developing or encountering any sexual friction, experimentation or desire with other young characters.

In marked contrast, Meg Rosoff's ambitious novel How I Live Now (2004), similarly set in a world without reliable or reassuring adult care or guidance, tackles 'taboo' subjects such as incest, anorexia, the threat of starvation, teenage sexuality, and arbitrary death and violence. The novel combines a poignant depiction of the intense bonds between cousins, especially between Daisy and her soul-mate Edmond, with a stark depiction of orphaned children's traumatic experiences. The interim authorities deliberately rupture the self-consciously insular and idyllic micro-community created by the cousins as it is considered inappropriate (even during the upheaval of wartime) to 
maintain the proper and traditional social institution of the family. The cousins are thus separated and are billeted with adults in different towns during the Occupation of the country. However, this artificial reconstruction of the family system by the authorities proves unsuccessful as Daisy and her younger cousin Piper resist this forced bonding with non-related adults and choose to attempt the dangerous journey back to their idealised rural family home. Daisy, surprised by the depth of her maternal feeling, is forced to become protector and guardian of Piper while attempting a reunion with their biological family. While Daisy assumes the traditionally 'masculine' role of leader during this painful trek where the threat of starvation is never far away, this is counterbalanced by an increase in her self-image as a young woman and a less anxious engagement with her female body as her eating disorder gradually diminishes over time.

The closure of this novel involves a delicate balance between optimism and pessimism and between the radical assertion of female agency and the patriarchal expectation of feminine compliance and passivity. Although Daisy is eventually reunited with her 'true' family in England after her forced evacuation from England to America, this triumph over divisive forces is blunted by her acceptance of Edmond's damaged and changed nature, and of the fact that they will never be able to regain their youthful innocence. The traditional 'fairy-tale' assumption of the male heroic figure rescuing the damsel-in-distress is challenged and inverted at the end of the novel when Daisy is the one to strive to rescue and re-awaken Edward from his traumatised isolation. Daisy comments that the story of her experiences were not concluded because of the missing section to the story of their experiences: 'The one where the hero [Edward] comes home to find me gone' (Rosoff 2004, p.183). Significantly, this longed for though painful reunion of young lovers takes place in a garden, the traditional image of pre-lapsarian innocence, while the ambivalent nature of the enclosed garden's white blossoms balances the insular nature of their love against the potential for rebirth and hope for the future, albeit in 'a country deformed and misshapen by war' (Rosoff 2004 , p.185). The domestic and once idyllic space of the family garden is now charged with political pain and traumatic memories as the damaged private sphere of the home is implicitly conflated with the macro-political arena of the wounded state of the nation. As Valerie Krips has observed, the symbolic ability of physical houses to incorporate the macro-political aspects of belonging is a common motif in texts addressing issues of political belonging and national identity: 'Houses often become metaphors for 'the house of England' in children's books where nationalism or imperialism is part of the narrative' (Krips 2000, p.136).

While Daisy's first reluctant relocation to England is dictated by her parents, her later choice to ultimately settle in England with her English family is therefore both a confident manifesto of independence against her father's patriarchal authority, and a desperate attempt to regain the interdependent model of a supportive community of her peers by living with her cousins. Daisy's instinctive affinity with the ancient, meandering ancestral house of her cousins, which she regards as quintessentially English, intriguingly suggests an ambivalent yearning for a sense of identity within the social and physical landscape of the home, where her need to assert individuality within the mico-society of the family competes with the stillcompelling allure of the 'mother' country. Yet although Rosoff does depict Daisy's unfamiliarity, amusement and occasional impatience with local English society and customs, there is little explication of the impact of Daisy's engagement with modes of social control on her understanding of what can and should constitute belonging to a larger community. In particular, the opportunity to explicitly address the international tensions causing the war which dominates the novel and precipitates Daisy's painful journey towards more reflective self-actualisation, is disappointingly unfulfilled, while Daisy's repeated choice of general and oblique descriptions of the occupying enemy forces, who are non-English foreigners like her, precludes any further exploration of her engagement with issues of the negotiation of national and ethnic identity and the power relations of colonisation.

However, Rosoff does recognise that the characters' traditional notions of reliable and safe markers of national and cultural identity which demarcate 'them' from 'us' are compromised and blurred by the insidious threat of violence from internal and native enemies as well as external foes. 
Despite Daisy's determined lack of interest in the details of how the war and the Occupation began, she does note the reactionary media treatment of the personal and political tensions during the tenuous cease-fire at the end of the novel: 'The tabloids waxed nostalgic for the good old days of WWII, when The Enemy all spoke a foreign language and the army went somewhere else to fight' (Rosoff 2004, p.168). There seems to be a disturbing erasure of cultural and ethnic difference among the English characters in the novel, who are all portrayed as white, fairly privileged and middle-class.

Sedgwick's novel Floodland (2000), which also explores the potential for young female characters' heroic agency in a fragmented, reactionary and conflicted near-future England, also disappointingly omits the multicultural dimension despite its depiction of the forced ongoing evacuation of all of the low-lying regions of the United Kingdom. All the characters are white and English, with no apparent awareness or inclusion of characters from other national, racial or ethnic backgrounds.

This lack of an expansive comprehension of how selfactualisation and an inclusive identity politics can enrich each other is also implicit in the novel's presentation of the clash between such traditional binary systems as the pull of the past and the claims of the present, the power of technology and the dominion of nature, the claims of obedience to parents and the need for individual autonomy, and between 'civilisation' and religious belief on the one hand, and violence and barbarism on the other. The sole means of transport and communication between the remaining outposts of humanity is that of boats which traverse the liminal space of the sea, which now has reconfigured the once-domesticated and controlled landscape into an alien and hostile environment comprising water and land. Zoe's painful experiences of isolation in Floodland seem to outweigh any possibility for enriching and equal relationships with others, whether child or adult. Her most dangerous threat comes not from the elements but from the hostile attentions of her peers during her encounter with a tribal community led by children subsisting on a floating 'monstrous cathedral' (p.93) which constitutes the 'Island of Eels,' where torture and violence are commonplace. This once sacred and privileged space has been forcibly occupied by desperate refugees and turned from a sanctuary of peace to a defensive fortress governed by vicious teenagers. Zoe encounters a series of untenable, unsatisfactory communities and places during her quest to be reunited with her parents, now living in the symbolically named town of Newhome.

Despite Zoe's desire to re-submit to adult authority, it is suggestive that she originally precipitates this separation and break-up of the family unit by her assumption of the right to decide that when the rescue boat arrives her father will stay with his sick wife, already aboard, rather than his vulnerable young daughter. Zoe ensures that her father is spared that choice, an interesting display of her ability to assume a convincing 'adult' power over an older and more experienced authority figure who is depicted as less able and resolved to deal with a too-difficult situation. Yet Zoe's legitimate anger and feelings of betrayal at her parents' lack of efforts to find her are unconvincingly melted away in the final page of the book by her discovery of the alleged reason of their neglect: her mother's illness after the birth of her new baby brother. I would argue that despite the insights that this narrative offers regarding female selfactualisation, the contrived tableau at the end of the novel, where the five members of the artificially reconfigured family (including the tacitly adopted Munchkin) re-form with the children safely under the protection and authority of adults, seems forced and inconsistent, given that the emphasis throughout the novel was on Zoe's painful acceptance of the need for children's self-sufficiency and the inevitability of the selfish drives of both child and adult human nature. It would seem that Roberta Seelinger Trites' conclusion, in her book Disturbing the Universe: Power and Repression in Adolescent Literature, is accurate in light of this 'happy ending': 'the underlying agenda of many YA novels is to indoctrinate adolescents into a measure of social acceptance' (Trites 2000, p.27) of inherited social systems.

Of the four dystopian novels I consider, Gary Kilworth's The Electric Kid (1994) most explicitly addresses both the constant vulnerability of children from adults' control and abuse and the empowering possibilities for co-operative child communities which welcome female leadership. Kilworth's novel investigates the sustainability of a 
micro-society created by children and young people's ability to successfully care for each other without an imposed adult framework. In the midst of an alienating near-future urban wasteland, where disenfranchised young people and obsolete technology are considered equally inconvenient and disposable, these multicultural orphan dump-children scrounge a living by renovating discarded electronic equipment and selling these improved versions onto adults. These marginalised young people must learn to be creative problem solvers in their transformation of the detritus of their society's past in order to enable their economic and physical survival. Traditional associations of masculinity with technological power and feminine identity with the world of nature are challenged as an affinity with technology serves to both empower and also to endanger both the young protagonists throughout the novel. With Blindboy's special talent for hearing and differentiating tones from electronic junk and Hotwire's instinctive ability to fix anything electronic that she scavenges, they are forced to work for the nefarious Mouseman. They eventually succeed in saving the city from Mouseman's attempt to destroy it, and Kilworth provides an appropriately subdued 'happy' ending with the two children, now working for a trustworthy adult employer, able to ensure fair treatment and payment for the work of the other dump children. On the final page of the novel, there is suggested the possibility of these children's superior potential for the advancement of computer technology in their joint plans to create a unique cybernetic device which will provide Blindboy with sight. Thus, the possibilities for a transformation of gender politics as demonstrated by egalitarian and reciprocal friendships based on mutual respect and affection between male and female young characters are proposed through the microfamily formed by Blindboy and Hotwire along with the other dump children.

Although Kilworth does not sentimentalise the precarious existence of the dump children, he does emphasise and affirm the supportive and protective nature of this community of displaced children who rely on each other for protection against hardship and the threat of adult predators. While Hotwire does occasionally feel isolated and neglected by her motley co-scavengers, the other dump children heroically come to her defence when she is threatened by armed adult criminals late in the novel: 'My pals had saved me....They cared about me and each other after all. When it came down to it, a threat to one was a threat to all' (Kilworth 1994, p.130). Significantly, both Hotwire and Blindboy choose an allegiance and preference for this unconventional coalition of displaced children over the alluring possibility of belonging to a traditional family structure, when they resist the overtures of the policeman who has become interested in their case, and of his wife, who is always seen to occupy the domestic, private sphere of their apartment.

The motif of rubbish serves as a powerful metaphor for the way in which adult society regards the dump children as expendable, but it also serves to celebrate the male and female protagonists' resourcefulness and their capacity to transform broken trash into useful objects. This ambivalence regarding both the simultaneous exploitation of children as vulnerable and marginalised figures by adults and also the recognition of the potential of children's ability to renovate objects of the past, abandoned by adults as broken and beyond repair, provides a thoughtful aspect to the exciting adventure and urban survival story in this novel. Kerry Mallan has argued in her article 'Trash aesthetics and utopian Memory: The tip at the End of the street and The Lost Thing', that a rubbish tip, 'the terminus for society's waste, a dumping ground for the unwanted, broken and used' is 'a juxtaposition in a real place of several incompatible sites' (Mallan 2005, p.30) and thus can be regarded as a heterotopia, according to Foucault's theory of how certain social spaces such as prisons, cemeteries, trains and boarding schools are embedded in the dialectic between power and knowledge. Mallan's discussion of the ambivalent potential of trash's containment of both physical discarded merchandise and knowledge abandoned by society is useful in serving to elucidate the importance of memory combined with a dynamic yet reflective connection to the past in dystopian fiction.

This successful recovery and re-energising of culture and personal and collective memory becomes an instrumental tool for these young female protagonists in their search for both effective self-expression and transformation of the old order into building a more satisfactory and child-centric society. The power of storytelling to act as both a medium 
for social cohesion in a time of social fragmentation and as a means of enabling a more secure sense of female subjectivity is a central trope in all of the four novels. Storytelling affords possibilities for young people to create own original stories and to assume the imaginative authority and role of inspiring and instructional storytellers for their peers. This recognition and celebration of children's original voices is counterbalanced by the depiction of the ongoing relevance and value of stories that they have inherited from the past, transmitted to them by adults, in supporting the children to cope with their problems and challenges in this world without adult guidance or intervention. For these inherited narratives also forge a link with past ideological disciplinary codes which may have no relevance in this radically changed future. Therefore these stories may afford both empowering and regulatory possibilities for informing and contextualising young people's potential for the re-imagination of future societies.

For example, Daisy in How I Live Now, once forced to relocate to America, feels compelled to record and write down her own personal history, the painful process of which is crucial for her gradual assimilation of her traumatic experiences into providing both a reflective connection to the past, and a dynamic foundation for her future plans to be reunited with her cousins: 'The only help for my condition, then as now, is that I refused to let go of what I loved. I wrote everything down, at first in choppy fragments; a sentence here, a few words there, it was the most I could stand at the time. Later I wrote more, my grief muffled but not erased by the passage of time' (Rosoff, 2004 p.159). The novel contains an implicit double-voicedness as it is narrated retrospectively by an older, wiser Daisy but told from the viewpoint of a younger Daisy. Rosoff's emphasis is on the value of individual efforts at grappling with issues of identity over time through the medium of a personal narrative, such as a diary. However The Electric Kid addresses narrative's role as a supportive medium for maintaining a group identity in the process of acculturation. The dump kids ritualistically gather to meet every night in the same place in the dump for the regular performances of 'storytelling' (Kilworth 1994, p.40). To Hotwire and her fellow orphans this affords a regular vehicle for bonding and a sense of community, not merely an opportunity for entertainment and distraction from their everyday cares. Different children, both male and female, occupy and perform the role of storyteller in different nights, providing them with a productive and reciprocal experience as both originator and audience of these shared narratives.

In The Girl Who Owned a City, Lisa initially claims the status of storyteller as she tells her young brother Todd parables reflecting their own experiences, using these tales to clarify her own confused feelings while seeking to comfort her young sibling. These stories punctuate the novel and bind the siblings closer together. Lisa compares herself to the inquisitive heroine Goldilocks when she is forced to break into a deserted farmhouse for supplies, and she draws on the legends of King Arthur and Camelot when she is considering secure locations for the settlement of local children that she is planning: 'What they needed was a castle with high walls and a moat, like in the days of King Arthur' (Nelson 1995, p.11). Lisa's deployment of and tacit identification with this heroic figure conjures up intriguing associations: the reinvention of a reactionary, feudal and patriarchal community with a strict power hierarchy, now under the leadership of a modern young girl, and also the romanticised aura of a society founded on a more egalitarian and reflective ethos which denounces conventions of 'might making right'.

Whereas Lisa self-consciously forges a link with past stories by creating a vision of herself as a reincarnation of King Arthur, Sedgwick frames the journey of his protagonist Zoe in Floodland with intertextual references to the visionary poetry of William Blake which are transmitted to her by one of the adults in the novel, who shares the same name as the poet. Initially frustrated and intrigued by William's seeming rambling conversations and 'crazy stories' (Sedgwick 2000, p.47) which revolve around the apocalyptic destruction of communities in Blake's epic poem 'Jerusalem: The Emanation of the Giant Albion', Zoe ultimately comes to agree with William's declaration of narrative's crucial role in socialisation, power relations and in defining a fulfilling sense of self: "WWhat's the point in surviving if you forget how to be human?" said William. "Stories walk the truth into existing"' (Sedgwick 2000, p.81). Tellingly naming the boat, which Zoe utilises 
as a means of survival, after the heroine, Lyca, of Blake's 'Little Girl Lost' poem,

Sedgwick addresses young people's need for inheriting narratives from the past while adapting and reinterpreting them to be compatible with the radical changes in the dystopian near-future world. William's obsessive though garbled reiteration of the destruction of the known world and the epic emergence of a new system of belief involving 'a story about a boat' (Sedgwick 2000, p.47), an allusion to the Biblical story of Noah and the repopulation of the world after a devastating flood, tacitly recasts this epic story with a young female protagonist as hero and saviour of her people. This intertextual context intriguingly hints at the possibility for Zoe's contribution to and possible redemption of the nascent adult society that she joins at the end of the novel, and provides a context for the reader in which to view Zoe's survival and future life. Yet, as observed earlier, the radical transformative potential of Zoe's energy and heroic agency is depicted as safely channelled and re-stabilised into conservative power relations between authoritative adult and subordinate and silenced child in the closing pages of the narrative.

This ambivalent tone to the closure of stories about young female protagonists' spatial and psychological journeys is shared by all four of these novels. I would argue that the genre of dystopian fiction can provide valuable opportunities for young readers to reflect on the complex process of their engagement with the regulatory power relations of their communities. The possibilities for the expansion and reorganisation of the production of female personal identity and political belonging are addressed in these stories of displacement. Yet, despite these novels' empowering message of young female characters' potential for creating new configurations of spatial politics and new visions of future societies, it is the case that inherited regulatory systems such as the home and patriarchal authority seem to exert an overwhelming ideological pressure on restabilising these child-centric alternative communities as conservative social and spatial arrangements, embedded in traditional conventions of control and authoritarian power relations. The presence of the past, which can offer personal and social continuity, threatens to overshadow and indeed overwhelm the transformative potential of young adult protagonists in these dystopian future worlds.

\section{REFERENCES}

Alston, Anne (2005) 'Your room or mine? Spatial politics in children's literature', New Review of Children's Literature and Librarianship April 11, 1: 15-32.

Foucault, Michel (1979) Discipline and Punish: The Birth of the Prison. Translated by Alan Sheridan. Harmondsworth, Penguin.

Hintz, Carrie (2002) 'Monica Hughes, Lois Lowry and young adult dystopias', The Lion and the Unicorn April 26, 2: 254-263.

Kilworth. Gary (1994) The Electric Kid. London, Bantam.

Krips, Valerie (2000) The Presence of the Past: Memory, Heritage and Childhood in Post-War Britain. London, Garland.

Kristeva, Julia (1982) Powers of Horror: An Essay in Abjection. Translated by Leon. S. Roudiez. New York, Columbia University Press.

Mallan Kerry (2005) 'Trash aesthetics and utopian memory: The Tip at the End of the Street and The Lost Thing', Bookbird 43, 1: 28-34.

Nelson O.T. (1995) The Girl Who Owned a City. Revised Edition. Minneapolis, First Avenue Editions.

Rosoff, Meg (2004) How I Live Now. London, Penguin.

Sambell, Kay (2004) 'Carnivalising the future: A new approach to theorising childhood and adulthood in science fiction for young readers', The Lion and the Unicorn April 28, 2: 247-267.

Sargent, Lyman Tower (1994) 'The three faces of utopianism revisited', Utopian Studies 5, 1: $1-37$.

Sedgwick, Marcus (2000) Floodland. London, Orion. 
Stephens, John (ed) (2002) Ways of Being Male:

Representing Masculinities in Children's

Literature and Film. Routledge, New York.

Trites, Roberta Seelinger (2000) Disturbing the Universe: Power and Repression in Adolescent Literature. Iowa City, University of Iowa Press.

Walsh, Kevin (1992) The Representation of the Past: Museums and Heritage in the PostModern World. London, Routledge.

\section{BIOGRAPHICAL NOTE}

Patricia Kennon is Lecturer in English Literature and Children's Literature at Froebel College of Education, Dublin, Ireland. Her Ph.D. explored the representation of manliness in later Victorian ficiton, and her research interests centre on nineteenth-century children's literature in relation to its cultural, social and political contexts, and contemporary young adult literature, with particular focus on gender and sexuality. 